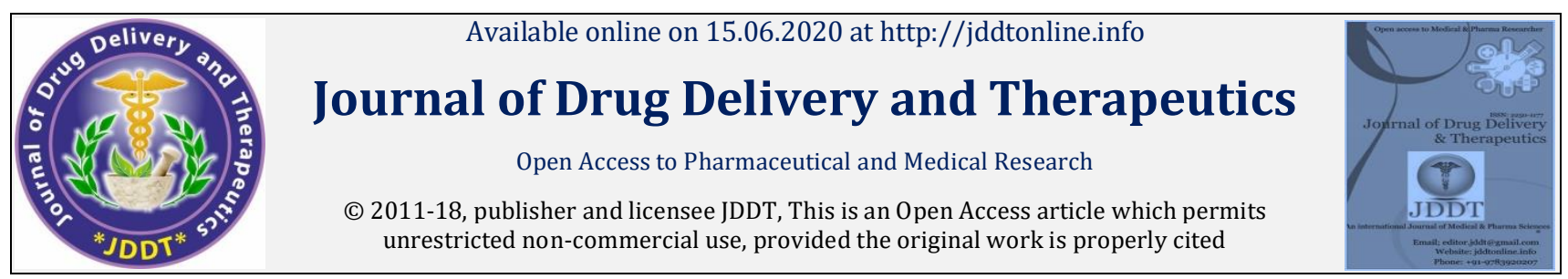

Open 1 Access

Research Article

\title{
Development and Validation of UPLC-MS/MS Method for Rapid Simultaneous Determination of Levothyroxine and Liothyronine in Human Serum
}

\author{
Dutt Rohit ${ }^{1 *}$, Malik Kailash Chander ${ }^{1}$, Karwa Manoj'2, Jain Gaurav Kumar ${ }^{3}$ \\ ${ }^{1}$ Department of Pharmacy, School of Medical and Allied Sciences, G D Goenka University, Gurugram-122103, India \\ 2 Auriga Research Private Limited, Plot no. 136, Sector-5, IMT Manesar, Gurugram, India \\ ${ }^{3}$ Department of Pharmaceutics, School of Pharmaceutical Sciences, Delhi Pharmaceutical Science and Research University, New Del hi, India
}

\begin{abstract}
A simple ultra-high performance liquid chromatography coupled with tandem mass spectrometry (UPLC-MS/MS) method was developed and fully validated to simultaneously determine levothyroxine (LT4) and liothyronine (LT3) in human serum. Sample preparation was done through protein precipitation with acetonitrile. HyPURITY C18 column was selected to achieve rapid separation for LT4 and LT3 within 4 min. Electrospray ionization (ESI) under multiple reaction monitoring (MRM) was used to monitor the ion transitions for LT4 (m/z 777.54 $\rightarrow 731.52$ ), LT3 $(\mathrm{m} / \mathrm{z} 651.64 \rightarrow 605.65)$ and internal standard LT4-D3 (m/z 780.53 $\rightarrow 734.19)$, operating in the positive ion mode. The method was proved to be accurate $(82.35 \%$ to $113.56 \%)$ and precise $(0.73 \%$ to $8.28 \%$ ) over concentration range of $50.37 \mathrm{ng} / \mathrm{ml}-300.13 \mathrm{ng} / \mathrm{ml}$ for $\mathrm{LT} 4 \mathrm{and} 0.5$ $\mathrm{ng} / \mathrm{ml}-50.37 \mathrm{ng} / \mathrm{ml}$ for LT3. The validated method could be applied for pharmacokinetic study or bioequivalence testing of combination products of LT4 and LT3.
\end{abstract}

Keywords: Levothyroxine; Liothyronine; Ultra Performance Liquid Chromatographic; Mass Spectrometry; Human Serum

Article Info: Received 19 March 2020; Review Completed 26 May 2020; Accepted 06 June 2020; Available online 15 June 2020

Cite this article as:

Dutt R, Malik KC, Karwa M, Jain GK, Development and Validation of UPLC-MS/MS Method for Rapid Simultaneous Determination of Levothyroxine and Liothyronine in Human Serum, Journal of Drug Delivery and Therapeutics. 2020; 10(3-s):176-181 http://dx.doi.org/10.22270/jddt.v10i3-s.4189

*Address for Correspondence:

Dutt Rohit, Department of Pharmacy, School of Medical and Allied Sciences, G D Goenka University, Gurugram-122103, India

\section{INTRODUCTION}

Hypothyroidism is a state of deficiency of endogenously produced thyroid hormone and affects nearly $5.0 \%$ of the world population 1 . Hypothyroidism management is done with monotherapy of levothyroxine (LT4). Levothyroxine is a synthetic analogue of thyroxine hormone and is used in concentration equivalent to thyroid stimulating hormone (TSH) present in the body 2,3. Although, treatment with LT4achieve normal TSH levels, but $5-10 \%$ of individuals with hypothyroidism are not satisfied with monotherapy, and do not consider their previous well-being to be restored $4-6$. The more potent thyroid hormone is triiodothyronine (T3), $20 \%$ of which is produced by the thyroid gland and rest $80 \%$ is produced by conversion of thyroxine (T4) to T3 in the liver 7. So under physiological conditions, a treatment dependent singly on LT4 would not give optimum results as required level of T3 will not be met. Several studies in the past demonstrated that treatment with combination of LT4 and liothyronine (LT3), the man made form of T3 is preferred compared to monotherapy by LT4 ${ }^{4-6}$. First, studies in thyroidectomized rats have demonstrated that normal tissue concentrations of $\mathrm{T} 4$ and $\mathrm{T} 3$ can be reached by continuous infusions of LT4 and LT3 simultaneously ${ }^{7}$. In 1970s, human studies on the treatment of hypothyroidism used pharmacological doses of thyroid hormone combinations. Several clinical trials demonstrated that combinations of $\mathrm{LT}_{4}$ and $\mathrm{LT}_{3}$ are beneficial and considered as answer to the relatively frequent complaint of the persistence of hypothyroid symptoms with LT4 alone, despite normal TSH levels ${ }^{8}$. Combination therapy with LT4 and LT3improved several indexes of quality of life, mood, and psychometric performance ${ }^{4}$. Considering this, several combination products of LT4 and LT3are available in market and continuous monitoring of serum levels of LT4 and LT3 are required for effective therapy. Most clinical laboratories uses automated radioimmunoassay kits ${ }^{9}$, HPLC 10 and HPLCMS/MS 11 for measurement of free or total $\mathrm{T}_{4}$ and $\mathrm{T}_{3}$, however most of the developed methods are focused on determination of thyroid hormones from diagnostic purpose. 
Till date no analytic technique is available for determination of LT4 and LT3 in human serumfrom pharmacokinetic or bioequivalence purpose. In the present research, we have developed rapid and sensitive UPLC-MS/MS method for simultaneous determination of LT4 and LT3 in human serum using Levothyroxine D3 Hydrochloride (LT4-D 3 ) as internal standard (Fig. 1). The method could be utilized for determination of bioequivalence and serum concentrations following administration of LT4 and LT3 combination therapy.
(A)<smiles>N[C@@H](Cc1cc(I)c(Oc2cc(I)c(O)c(I)c2)c(I)c1)C(=O)O</smiles>

(B)<smiles>N[C@@H](Cc1cc(I)c(Oc2ccc(O)c(I)c2)c(I)c1)C(=O)O</smiles>

(C)<smiles>[2H]c1c(I)c(Oc2cc(I)c(O)c(I)c2)c(I)c([2H])c1C[C@]([2H])(N)C(=O)O</smiles>

Figure 1:

\section{MATERIAL AND METHODS}

\section{Materials}

LT4sodium (99.82\%), LT3 (99.81\%) and internal standard LT4-D3 hydrochloride (99.65\%) were obtained from Vivan Life Sciences Pvt. Ltd. (Mumbai, India). Acetonitrile, methanol and ethyl acetate of HPLC Grade was obtained from Merck Ltd. (India). HPLC water was produced by Milli Q purification system in laboratory using Millipore, (Bellerica, MA, USA).Glacial acetic acid(SQ Grade), Liquor Ammonia(SQ Grade) was obtained from Thermo Fisher Scientific India Pvt. Ltd (India).All other reagents were of analytical grade. Human Serum containing odium heparin as anticoagulant was procured from Darpan Diagnostic Research Solution (Gujrat, India) and stored at $-20 \pm 5^{\circ} \mathrm{C}$ and $-70 \pm 15 \stackrel{\circ}{ } \mathrm{C}$.

\section{Chromatographic and Mass Spectrometric Conditions}

The samples were chromatographed and analyzed on UPLC (Waters Corporation, MA, USA) with MS detector (Synapt; Waters, Manchester, UK) havingHypurityC18 (50 X 4.6mm, 5 micrometer) UPLC column. The column oven and autosampler temperature were maintained at $40{ }^{\circ} \mathrm{C} \pm 5^{\circ} \mathrm{C}$ and $5^{\circ} \mathrm{C} \pm 0.5^{\circ} \mathrm{C}$, respectively. The sample injection volume was $20 \mu \mathrm{L}$ and elution was performed using $0.1 \%$ glacial acetic acid in water (mobile phase A):acetonitrile(mobile phase B) mixture $(65: 35, \mathrm{v} / \mathrm{v})$ with isocratic flow rate of $0.8 \mathrm{~mL} / \mathrm{min}$ and total run time of $4 \mathrm{~min}$. Waters Q-TOF Premier (Micromass MS Technologies, Manchester, UK) mass spectrometer was used for $\mathrm{m} / \mathrm{z}$ analysis. Different parameters are set as follow, desolvation gas at $950 \mathrm{l} / \mathrm{h}$, the cone gas at $20 \mathrm{l} / \mathrm{h}$, source temperature at $150^{\circ} \mathrm{C}$, capillary voltage at $4.0 \mathrm{kV}$ and sample cone voltage at $30 \mathrm{~V}$. LT4, LT3 and LT4-D $\mathrm{D}_{3}$ were analyzed by mass spectrometer with electro spray ionization in positive polarity mode. Precursor $\rightarrow$ product ion transition was found out to be $\mathrm{m} / \mathrm{z}$ $777.54 \rightarrow 731.52$ for LT4, $\mathrm{m} / \mathrm{z} 651.64 \rightarrow 605.65$ for LT3, and $\mathrm{m} / \mathrm{z} 780.53 \rightarrow 734.19$ for LT4-D3 at collision energy of $18 \mathrm{eV}$ and dwell time of $0.1 \mathrm{~s}$. Mass Lynx software version 4.1 was used for acquisition of The chromatographic data. The bestfit lines using weighting factor (1/Concentration2) linear least square regression analysis were obtained by peak area ratio of LT4 and LT3 to IS (LT4- D3). In serum samples the concentration of Levothyroxine and Liothyronine was estimated using linear regression factors to corresponding calibration curve.

\section{Calibration and Quality Control Samples}

Stock solution of LT4 and LT3 was prepared by dissolving the known quantity of drugs in $1 \mathrm{ml}$ of aqueous ammonia solution (5\%).Blank human serum was used to prepare calibration standards and QC samples by diluting corresponding stock solutions. Working dilutions for serum spiked calibration curve were prepared in the range of 50.37 $\mathrm{ng} / \mathrm{ml}-300.13 \mathrm{ng} / \mathrm{ml}$ for LT4 and in concentration range of $0.5 \mathrm{ng} / \mathrm{ml}-50.37 \mathrm{ng} / \mathrm{ml}$ for LT3. Dilutions for LOQQC, LQC, MQC and HQC quality control samples were also prepared from respective stock solution by suitable dilution. LT4-D3 (IS) dilution was prepared at concentrations of $250 \mathrm{ng} / \mathrm{ml}$. All stock solutions, calibration standards and QC samples were cryo-preserved under $-80^{\circ} \mathrm{C}$

\section{Sample Preparation}

Hundred microliter of LT4-D3, $100 \mu \mathrm{L} 0.5 \mathrm{~N} \mathrm{HCl}$ and $800 \mu \mathrm{L}$ of acetonitrilewas added to $200 \mu \mathrm{L}$ of sample (calibration, $\mathrm{QC}$ or serum) and vortexed for 5.0 minutes. After adding $1.5 \mathrm{~mL}$ of ethyl acetate, the mixture was centrifuged at $4000 \mathrm{rpm}$ at $4{ }^{\circ} \mathrm{C}$ for 5 minutes. The $2 \mathrm{~mL}$ supernatant was collected and allowed to dry at $20 \mathrm{psi}$ pressure and $50^{\circ} \mathrm{C}$ in nitrogen evaporator. Finally, the dried sample was reconstituted with $400 \mu \mathrm{L}$ mixture of $0.1 \%$ glacial acetic acid in water and acetonitrile $(65: 35 \mathrm{v} / \mathrm{v})$. The sample was then transferred into labelled auto sampler vials and inject into LCMS/MS system.

\section{Method Validation}

The method was validated in terms of selectivity, sensitivity, linearity, precision and accuracy. The precision of the 
method was evaluated with repeatability and intermediate precision assays. Within a day three concentrations in linear range and in seven replicates were used to evaluate repeatability whereas 3 concentrations in three replicates for a time interval of seven days were used to estimate intermediate precision. Accuracy was determined through intra-assay and inter-assays based on the standard solutions of analytes in three concentration levels. ICH guidelines were followed for validation of all parameters like selectivity, linearity, precision, accuracy, recovery, stability, detection limit, quantitation limit and ruggedness 12 .

\section{RESULTS AND DISCUSSION}

\section{Sample Preparation and Method Development}

Sample preparation is a key procedure for the determination of analytes in biological samples. In the present work for MS/MS determination, we have used simple liquid extraction and sample preparation procedure, to eliminate the possible interfering substances. Protein precipitation via acetonitrile was found suitable for the estimation of LT4,
LT3 and LT4-D3 in serum. As shown in Fig. 2, a clean chromatograms of LT4, LT3 and LT4-D3 in serum were obtained. HyPURITY C-18 column and high pressure applied in UPLC allowed rapid detection of LT4, LT3 and LT4-D3 with excellent peak shape. The composition of mobile phase was optimized through several trials to obtain symmetric peaks with good response. Elution with $0.1 \%$ glacial acetic acid in water: acetonitrile mixture $(65: 35, \mathrm{v} / \mathrm{v})$ with flow rate of $0.8 \mathrm{~mL} / \mathrm{min}$ allowed separation of LT4, LT3 and LT4D3 at retention time of 2.65, 1.67 and 2.56, respectively. The total run time was $4 \mathrm{~min}$.

The analysis of all the analytes were done in positive ion mode. Protonated molecules $[\mathrm{M}+\mathrm{H}]+{ }^{+}$at $\mathrm{m} / \mathrm{z} 651.64$ for LT3, 777.54 for LT4 and 780.53 for LT4-D3 were selected as the precursor ions for further fragmentation. ESI-MS/MS spectra in positive ion mode demonstrated that the dominant fragment of LT3 was $\mathrm{m} / \mathrm{z} 605.65$, for LT4 was $\mathrm{m} / \mathrm{z} 731.52$ and for LT4-D3 was 734.19. The most abundant ions, $[\mathrm{M}+\mathrm{H}-\mathrm{HCOOH}]^{+}$, represent the loss of $\mathrm{HCOOH}$ in thyroid hormones (Table 1).

Table 1: Precursor $\rightarrow$ Product ion transition for LT4, LT3 and LT4-D3 using Mass spectrometry

\begin{tabular}{lcccc}
\hline Mass (Da) & Levothyroxine & Liothyronine & Levothyroxine D3 \\
\cline { 1 - 1 } Parent Mass & 777.54 & 651.64 & 780.53 \\
Product Mass & 731.52 & 605.65 & 734.19 \\
\hline
\end{tabular}

(A)

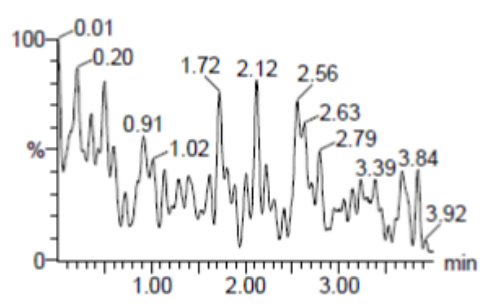

(B)

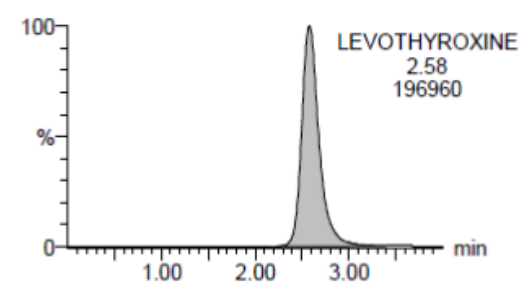

(C)

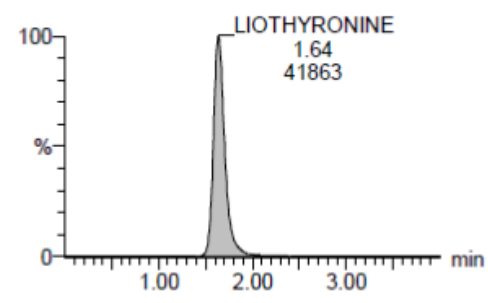

Figure 2:

\section{Specificity and Selectivity}

Eight lots of serum including haemolyzed and lipemic serum anticoagulant were evaluated and none showed significant interfering peaks at the retention time of LT4, LT3 and LT4D3, demonstrating that the developed method is specific and selective.

\section{Linearity}

The linearity determination of the LT4 and LT3 was done using weighted least square regression analysis of standard plot associated with eight-point standard curve. The calibration was found to be linear from $5.01 \mathrm{ng} / \mathrm{mL}$ to $300.13 \mathrm{ng} / \mathrm{mL}$ for $\mathrm{LT} 4$ and from $0.50 \mathrm{ng} / \mathrm{mL}$ to $50.37 \mathrm{ng} / \mathrm{mL}$ for LT3. Weighed least square regression analysis with weighting factor of $1 /$ Concentration $^{2}$ was used to determine best-fit calibration lines of chromatographic response versus concentration. As shown in Table 2, during the course of validation the coefficient of correlation $\left(\mathrm{r}^{2}\right)$ was found to be consistently greater than or equal to 0.98 , which is within acceptable limits.

Table 2: Linearity and Ruggedness data of LT4 and LT3 in serum samples

\begin{tabular}{|c|c|c|c|c|c|c|}
\hline & Analyte & $\begin{array}{c}\text { Calibration } \\
\text { range } \\
(\mathrm{ng} / \mathrm{mL})\end{array}$ & Slope & $\begin{array}{c}\text { Intercept } \\
\text { (ng/mL) }\end{array}$ & $\mathbf{R}^{2}$ & $\begin{array}{c}\text { LOQ } \\
\text { (ng/mL) }\end{array}$ \\
\hline $\begin{array}{c}\text { Standard } \\
\text { Solution }\end{array}$ & LT4 & $4.90-300.69$ & 0.00989103 & 0.00209728 & 0.995917 & 4.90 \\
\hline Ruggedness & LT4 & $5.01-300.13$ & 0.01048940 & 0.00293423 & 0.996859 & 4.91 \\
\hline $\begin{array}{l}\text { Standard } \\
\text { Solution }\end{array}$ & LT3 & $0.48-53.39$ & 0.0104997 & 0.00132268 & 0.995998 & 0.48 \\
\hline Ruggedness & LT3 & $0.50-50.37$ & 0.01140690 & 0.000737368 & 0.993674 & 0.47 \\
\hline
\end{tabular}




\section{Limit of Quantification (LOQ)}

LOQ is the lowest point of calibration curve representing lowest concentration that can be measured with precision and accuracy. The LOQ for LT4 and LT3, assessed by 3 calibration curve standards, was found out to be $4.9 \mathrm{ng} / \mathrm{mL}$ and $0.48 \mathrm{ng} / \mathrm{mL}$, respectively. The LLOQ precision forLT4 and LT3 was $0.66 \%$ and $2.42 \%$, respectively whereas the ULOQ precision for LT4 and LT3 was $1.40 \%$ and $0.35 \%$, respectively which are within acceptance limits.

\section{Accuracy and Precision}

The results of within batch and between batch accuracy and precision of the assay over the concentration range of LOQQC, LQC, MQC and HQC samples of LT4 and LT3 are shown in Table 3. Accuracy of the assay was measured as the absolute value of the calculated mean values of the $Q C$ samples to their respective nominal values, expressed as percentage using internal standard area ratio method and the precision was measured as the percent coefficient of variation. The within batch accuracy ranged from $88.77 \%$ to $109.58 \%$ and $82.35 \%$ to $112.78 \%$ for LT4 and LT3, respectively, whereas the between batch accuracy ranged from $86.69 \%$ to $109.58 \%$ and $82.35 \%$ to $113.56 \%$ for LT4 and LT3, respectively. The within and between batch precision was found to be $0.86 \%$ to $2.13 \%$ range and $0.73 \%$ to $8.28 \%$ range for LT4 and LT3, respectively. Thus data obtained indicate that the developed method is accurate and precise.

Table 3: Precision and Accuracy Assay data for LT4 and LT3 (n=6)

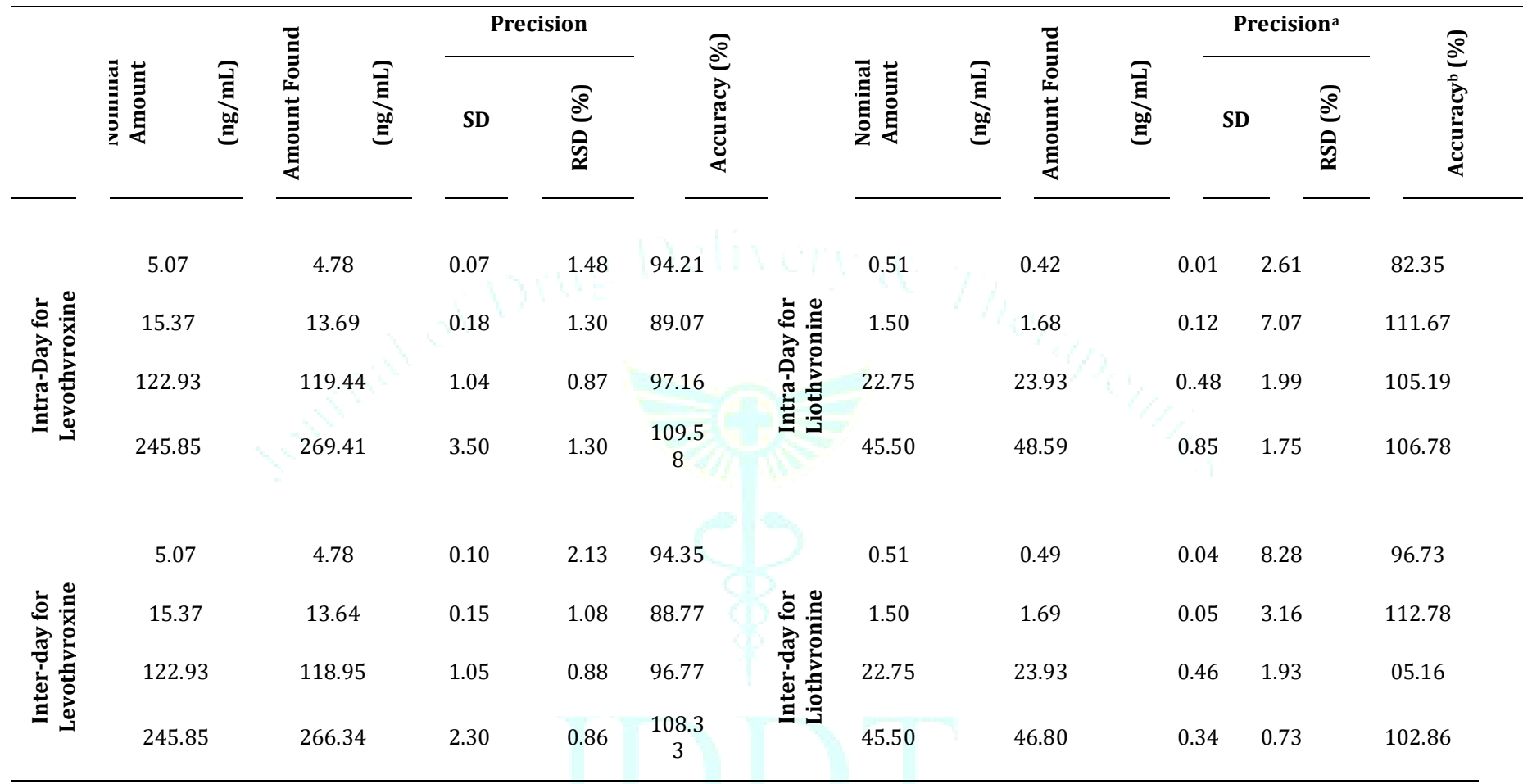

aPrecision as RSD \% (or CV\%) = (standard deviation divided / mean amount found $) * 100$

$\mathrm{b}$ Accuracy $=($ Amount found $/$ nominal amount $) * 100$

\section{Recovery}

The percentage recovery of LT4 and LT3 was calculated by determining the peak area response of spiked (extracted) quality control samples (LQC, MQC and HQC) against the peak area response of sample prepared by adding suitable amount of (extracted reconstituted) quality control samples (LQC, MQC and HQC) of equivalent concentrations (Table 4).
The percent recovery of LT4 and LT3 at LQC, MQC and HQC quality control samples were $49.69 \%, 50.20 \%, 55.51 \%$ and $56.37 \%, 56.36 \%, 56.64 \%$, respectively. For inter quality control sample of LT4 and LT3, the \% CV for recovery was $6.22 \%$ and $0.27 \%$ respectively, and is within limits. The Percent Mean of recovery were $51.80 \%$ and $56.46 \%$ which are within limits. The percentage recovery of LT4-D3 estimated by same procedure was found to be $50.45 \%$.

Table 4: Percentage Recovery for LT4 and LT3

\begin{tabular}{|c|c|c|c|c|}
\hline QC ID & Analyte & $A(\% \mathrm{CV})$ & B (\% CV) & $\begin{array}{c}\text { Extraction Recovery } \\
(\% \mathrm{RE})[\mathrm{A} / \mathrm{B} \times 100]\end{array}$ \\
\hline \multirow{2}{*}{ LQC } & Levothyroxine & $22177.50(3.31)$ & $46158.33,(0.53)$ & 48.05 \\
\hline & Liothyronine & 3124.17 (1.99) & $5572.33(2.03)$ & 56.07 \\
\hline \multirow{2}{*}{ MQC } & Levothyroxine & $197159.50(1.14)$ & $404294.17(1.57)$ & 48.77 \\
\hline & Liothyronine & $43036.00(1.31)$ & $77025.00(0.67)$ & 55.87 \\
\hline \multirow{2}{*}{ HQC } & Levothyroxine & $454419.17(0.82)$ & $837801.17(0.80)$ & 54.24 \\
\hline & Liothyronine & $88219.17(1.63)$ & $152761.50(5.72)$ & 57.75 \\
\hline
\end{tabular}

A: Mean Area response of six replicate samples prepared by spiking before extraction.

B: Mean Area response of six replicate samples prepared by spiking in extracted blank plasma. CV: Coefficient of variation. 


\section{Ruggedness}

The ruggedness of the extraction procedure and chromatographic method was evaluated by analysis of a batch of six sets of quality control samples and a set of calibration standard using a different column (same type) by another analyst. The intra batch accuracy ranged from $86.69 \%$ to $106.80 \%$ for LT4 and from $99.67 \%$ to $113.56 \%$ for LT3. The intra batch precision ranged from $0.47 \%$ to $2.21 \%$ for LT 4 and from $1.27 \%$ to $7.40 \%$ for LT3. The results (Table 2) clearly depicted that the batch was in the acceptance criteria for linearity, accuracy and precision data of the quality control samples. So the method met the criteria for ruggedness.

\section{Stability}

\section{Freeze thaw stability}

Three freeze-thaw cycles were performed to determine the stability of the spiked serum samples. LQC and HQC stability samples were taken in four replicates, kept at $-80^{\circ} \mathrm{C} \pm 10^{\circ} \mathrm{C}$ and then analyzed after three freeze thaw cycle against $\mathrm{QC}$ samples and freshly spiked calibration curve standards. The range of comparative stability was from $91.72 \%$ to $109.05 \%$ for LT4 and $103.24 \%$ to $113.33 \%$ for LT3, (Table 5).

\section{Bench top stability}

The bench-top stability was determined by analyzing four replicates of LQC and HQC stability sampleskept at room temperature for 4 hours against the freshly spiked calibration curve standards and QC samples (Table 5).The comparative stability ranged from $91.72 \%$ to $109.77 \%$ and $103.36 \%$ to $111.33 \%$ forLT4 and LT3, respectively.

\section{In-Injector stability}

Auto sampler stability was evaluated by analysis of LQC and HQC stability samples (four replicates), after processing and keeping them in Auto sampler for 2 Days 1 Hours \& 11 minutes, and then analysis was done against freshly spiked calibration curve standards and QC samples (Table 5). Comparative stability was found to be ranged from 88.79 $\%$ to $109.05 \%$ and $103.24 \%$ to $113.33 \%$ for LT4 and LT3, respectively.

Table 5: Stability data for Levothyroxine and Liothyronine under different conditions, $(n=6)$

\begin{tabular}{|c|c|c|c|c|c|c|c|c|c|c|c|c|c|}
\hline \multirow[b]{2}{*}{ 章 } & \multirow[b]{2}{*}{ 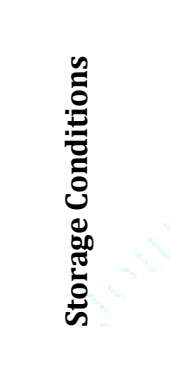 } & \multicolumn{6}{|c|}{ LT4 } & \multicolumn{6}{|c|}{ LT3 } \\
\hline & & 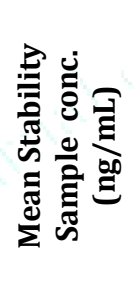 & 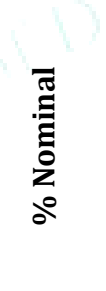 & 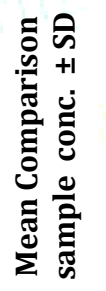 & 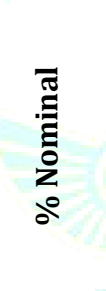 & 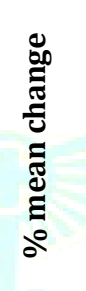 & 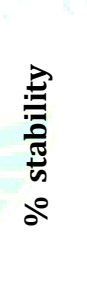 & 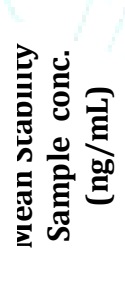 & 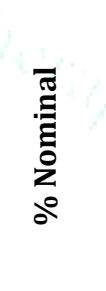 & 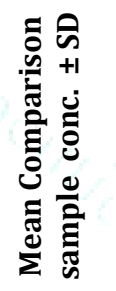 & 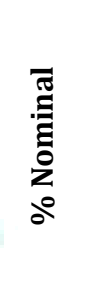 & 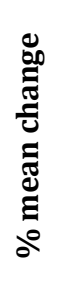 & 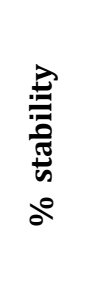 \\
\hline \multirow{2}{*}{$\begin{array}{c}\text { Freeze } \\
\text { and thaw }\end{array}$} & \multirow{2}{*}{$\begin{array}{c}\text { After } 3 \\
\text { cycles } 80^{\circ} \mathrm{C} \\
\pm 10^{\circ} \mathrm{C}\end{array}$} & 13.69 & 89.09 & $\begin{array}{c}14.06 \pm \\
0.17\end{array}$ & 91.72 & -2.63 & 97.13 & 1.62 & 107.83 & $\begin{array}{c}1.70 \pm \\
0.08\end{array}$ & 113.33 & $\begin{array}{c}- \\
4.70\end{array}$ & 95.15 \\
\hline & & 266.10 & 108.24 & $\begin{array}{c}269.66 \\
\pm 2.52\end{array}$ & 109.05 & -3.56 & 99.26 & 47.45 & 104.28 & $\begin{array}{c}46.18 \pm \\
0.28\end{array}$ & 103.24 & 2.75 & 101.01 \\
\hline \multirow{2}{*}{$\begin{array}{c}\text { Bench } \\
\text { Top }\end{array}$} & \multirow{2}{*}{$\begin{array}{c}4 \mathrm{hr} \text { at } 25 \pm \\
5^{\circ} \mathrm{C} \text { (Room } \\
\text { temp) }\end{array}$} & 14.05 & 91.40 & $\begin{array}{c}14.06 \\
\pm 0.17\end{array}$ & 91.72 & -0.07 & 99.65 & 1.73 & 115.50 & $\begin{array}{c}1.70 \pm \\
0.08\end{array}$ & 113.33 & 1.76 & 101.91 \\
\hline & & 267.22 & 108.69 & $\begin{array}{c}269.66 \\
\pm 2.52\end{array}$ & 109.05 & -0.91 & 99.67 & 45.11 & 99.14 & $\begin{array}{c}46.18 \pm \\
0.28\end{array}$ & 103.24 & $\begin{array}{c}- \\
2.31\end{array}$ & 96.02 \\
\hline \multirow{2}{*}{$\begin{array}{c}\text { Extracted } \\
\text { Sample } \\
\text { stability }\end{array}$} & \multirow{2}{*}{$\begin{array}{c}\text { Autosampler } \\
\left(6^{\circ} \mathrm{C}, 49 \mathrm{hrs}\right. \\
11 \mathrm{~min})\end{array}$} & 13.65 & 88.79 & $\begin{array}{r}14.06 \\
\pm 0.17\end{array}$ & 91.72 & -2.91 & 96.81 & 1.62 & 108.00 & $\begin{array}{c}1.70 \pm \\
0.08\end{array}$ & 113.33 & 4.70 & 95.29 \\
\hline & & 264.57 & 107.62 & $\begin{array}{c}269.66 \\
\pm 2.52\end{array}$ & 109.05 & $\begin{array}{c}- \\
2.077\end{array}$ & 98.69 & 46.94 & 103.15 & $\begin{array}{c}46.18 \pm \\
0.28\end{array}$ & 103.24 & 1.64 & 99.91 \\
\hline
\end{tabular}

$\%$ Mean change $=$ Mean stability samples - Mean comparison samples/mean comparison samples) $\times 100$.

\section{CONCLUSION}

We have successfully developed a specific, sensitive and rapid UPLC/ESI/MS/MS method for quantification of LT4 and LT3 in human serum and have validated the same. This assay method allowed real time analysis with simple liquid extraction procedure, isocratic chromatography condition using a reversed-phase column. An excellent performance was noted in terms of selectivity, linearity, precision, accuracy, recovery, quantitation limit and stability. Most importantly, short analysis run time of this particular method gives it an edge over all previously reported methods. Thus, this method is most appropriate for pharmacokinetic study, bioequivalence study and therapeutic monitoring of thyroid hormones.

\section{ACKNOWLEDGMENTS}

The authors are thankful to Ms. Anshul Gupta for providing linguistic assistance.

\section{CONFLICTS OF INTEREST}

There is no conflict of interest.

\section{REFERENCES}

1. Taylor PN, Albrecht D, Scholz A, Gutierrez-Buey G, Lazarus JH, Dayan CM, et al. Global epidemiology of hyperthyroidism and hypothyroidism. Nat Rev Endocrinol. 2018; 14(5):301-16.

2. Jacqueline Jonklaas, Bianco AC, Bauer AJ, Kenneth D. Burman, Cappola AR, Celi FS, et al. GUIDELINES FOR THE TREATMENT OF HYPOTHYROIDISM Prepared by the American Thyroid Association Task Force on Thyroid Hormone Replacement 
Division of Endocrinology , Georgetown University, Washington DC; 5 Division of Endocrinology, Rush University Medic. Thyroid. 2014; 24(12):1670-751.

3. Peterson SI, McAninch EA, Bianco AC. Is a normal TSH synonymous with "euthyroidism" in levothyroxine monotherapy? J Clin Endocrinol Metab. 2016;101(12):4964-73.

4. Escobar-Morreale HFF, Botella-Carretero JI, De Escobar GM. Treatment of hypothyroidism with levothyroxine or a combination of levothyroxine plus L-triiodothyronine. Best Pract Res Clin Endocrinol Metab. 2015; 29(1):57-75.

5. Clyde PW, Shakir KMM. in Primary Hypothyroidism. 2017. 290(22).

6. Biondi B, Wartofsky L. Combination treatment with T4 and T3 Toward personalized replacement therapy in hypothyroidism? J Clin Endocrinol Metab. 2012; 97(7):2256-71.

7. Escobar-Morreale HF, Obregón MJ, Hernández A, Escobar Del Rey F, Morreale De Escobar G. Regulation of iodothyronine deiodinase activity as studied in thyroidectomized rats infused with thyroxine or triiodothyronine. Endocrinology. 1997;
138(6):2559-68

8. Wiersinga WM. Paradigm shifts in thyroid hormone replacement therapies for hypothyroidism. Nat Rev Endocrinol [Internet]. 2014; 10(3):164-74. Available from: http://dx.doi.org/10.1038/nrendo.2013.258

9. Chopra IJ, Santini F, Hurd RE, Chua Teco GN. A radioimmunoassay for measurement of thyroxine sulfate. J Clin Endocrinol Metab. 1993; 76(1):145-50.

10. Shah RB, Bryant A, Collier J, Habib MJ, Khan MA. Stability indicating validated HPLC method for quantification of levothyroxine with eight degradation peaks in the presence of excipients. Int J Pharm. 2008; 360(1-2):77-82.

11. Kazemifard AG, Moore DE, Aghazadeh A. Identification and quantitation of sodium-thyroxine and its degradation products by LC using electrochemical and MS detection. J Pharm Biomed Anal. 2001; 25(5-6):697-711.

12. Bajaj S, Singla D, Sakhuja N. Stability testing of pharmaceutical products. J Appl Pharm Sci. 2012; 2(3). 